\title{
Un teatro di voci e di ombre. Marguerite Yourcenar sulla scena, a cura di Enzo Cordasco
}

\section{Vittorio Fortunati}

\section{(2) OpenEdition}

1 Journals

\section{Edizione digitale}

URL: http://journals.openedition.org/studifrancesi/6430

DOI: $10.4000 /$ studifrancesi.6430

ISSN: 2421-5856

\section{Editore}

Rosenberg \& Sellier

\section{Edizione cartacea}

Data di pubblicazione: 1 novembre 2010

Paginazione: 588-589

ISSN: 0039-2944

\section{Notizia bibliografica digitale}

Vittorio Fortunati, «Un teatro di voci e di ombre. Marguerite Yourcenar sulla scena, a cura di Enzo

Cordasco», Studi Francesi [Online], 162 (LIV | III) | 2010, online dal 30 novembre 2015, consultato il 09 janvier 2021. URL: http://journals.openedition.org/studifrancesi/6430 ; DOI: https://doi.org/10.4000/ studifrancesi.6430

Questo documento è stato generato automaticamente il 9 janvier 2021.

\section{(c) (1)}

Studi Francesi è distribuita con Licenza Creative Commons Attribuzione - Non commerciale - Non opere derivate 4.0 Internazionale. 


\title{
Un teatro di voci e di ombre. Marguerite Yourcenar sulla scena, a cura di Enzo Cordasco
}

\author{
Vittorio Fortunati
}

\section{NOTIZIA}

Un teatro di voci e di ombre. Marguerite Yourcenar sulla scena, a cura di Enzo CORDASCO, Perugia, CRACE, 2009, pp. 447.

1 Il lavoro che E. Cordasco, autore e critico teatrale, ha dedicato all'opera drammatica di M. Yourcenar è un libro decisamente sui generis, né monografia di uno studioso, né vera e propria miscellanea. Il curatore, infatti, raccoglie e integra in un discorso complesso, ma coerente, materiali delle più disparate provenienze: lettere e interviste della scrittrice, inediti, atti di convegni, saggi di importanti studiosi, recensioni, note di regia. Ne risulta un'intensa conversazione a più voci, che, dichiara $\mathrm{E}$. Cordasco, «ha l'intento di far conoscere il teatro yourcenariano un po' a tutti», ma soprattutto «di "spingere" gli operatori teatrali e quelli che lavorano nel vasto campo dello spettacolo a rappresentarlo di più, a confrontarvisi con coraggio, con intraprendenza e con grande senso di sfida» (Nota introduttiva, p. 11). Dopo un capitolo a carattere generale (Umana, troppo umana. Lettere, aneddoti, testimonianze per una Yourcenar più vicina..., pp. 17-61), in cui vengono ripresi alcuni dei più importanti dibattiti intorno al pensiero della scrittrice, dalla sua concezione dell'amore alle sue idee sulla storia, al suo controverso rapporto col movimento femminista, si passa alla disamina delle sue pièces teatrali, suddivise in due capitoli. Il teatro di Marguerite Yourcenar (pp.63-117) si apre singolarmente con Feux, raccolta di prose liriche di cui E. Cordasco sottolinea la natura di monologhi teatrali, per soffermarsi in seguito su Rendre à César, versione drammatica del romanzo Denier du rêve, sul Dialogue dans le marécage, atto unico ispirato al personaggio dantesco di Pia de' Tolomei, infine su La Petite Sirène, sorta di divertissement composto e messo in scena negli anni Quaranta negli Stati Uniti e pubblicato solo nel 
1970. Il mito greco (pp.119-176) raggruppa invece le originali riprese yourcenariane di alcuni dei più importanti miti della classicità: Électre ou la chute des masques, rivisitazione spregiudicata dell'Orestea di Eschilo, Qui n'a pas son Minotaure?, in cui il mito di Teseo non manca di agganci alla contemporaneità, per concludere con Le Mystère d'Alceste, tratto da Euripide. Il quarto capitolo, Teatro da leggere o da rappresentare? (pp. 177-202), affronta fin dal titolo una questione ancora aperta, esponendo diverse opinioni.

2 Successivamente vengono descritte le rappresentazioni di pièces di M. Yourcenar che hanno avuto luogo in Italia. La fortuna teatrale di Marguerite Yourcenar (pp. 203-239) si riferisce agli anni Ottanta e Novanta del secolo scorso e si sofferma, in particolare, sull'opera di tre uomini di palcoscenico: Luca Coppola, autentico pioniere del teatro yourcenariano nel nostro Paese, con Elettra o la caduta delle maschere (1984); Giorgio Albertazzi, con la sua drammatizzazione dei Mémoires d'Hadrien (Memorie di Adriano, ritratto di una voce), andata in scena per la prima volta nel 1989; Giancarlo Corbelli, con una rappresentazione del Dialogue (Dialogo nella palude, 1991-1992) che ha messo in rilievo le analogie della pièce con il genere tradizionale giapponese del Nô. Sono donne, invece, le protagoniste della sezione relativa alle esperienze più recenti (Gli anni 2000: il mito riprende, pp. 241-278): citiamo, per esempio, Anita Bartolucci, interprete della Clitemnestra in scena a Torino nella stagione 2004-2005; Isabel Russinova, che vestì $i$ panni di Elettra nel 2007, con la regia di Armando Pugliese; Valeria Parrella, autrice di Io, Clitemnestra. Il Verdetto (2007), che traspone il mito in ambiente camorristico.

3 Non poteva mancare un capitolo (pp. 279-344) dedicato a uno spettacolo ideato dallo stesso E. Cordasco: Delle donne il canto, tratto da Feux con l'inserimento di frammenti della raccolta lirica Les Charités d'Alcippe, rappresentato a Perugia nel maggio 2008. Lo spettacolo integra la lettura, la musica e la danza: in effetti, è proprio la contaminazione dei linguaggi, secondo l'autore, ad aprire nuove possibilità interpretative a opere spesso considerate poco adatte alla scena. 